Таратина Олеся Валериевна - канд. мед. наук, науч. сотр. отделения гастроэнтерологии, доцент кафедры гастроэнтерологии факультета усовершенствования врачей'; ORCID: http://orcid.org/0000-0001-6112-6609 $\bowtie$ 129110, г. Москва, ул. Щепкина, 61/2, Российская Федерация.

Тел.: +7 (926) 2456659.

E-mail: taratina.o@gmail.com

Белоусова Елена Александровна - д-р мед. наук, профессор, руководитель отделения гастроэнтерологии, заведующая кафедрой гастроэнтерологии факультета усовершенствования врачей'; ORCID: http://orcid.org/0000-0003-4523-3337

\footnotetext{
' Государственное бюджетное учреждение здравоохранения Московской области «Московский областной научно-исследовательский клинический институт им. М.Ф. Владимирского»; 129110 , г. Москва, ул. Щепкина, 61/2, Российская Федерация
}

Актуальность. Внекишечные проявления (ВКП) воспалительного заболевания кишечника (ВЗК) - атрибут его более тяжелого течения. Среди внекишечных проявлений ВЗК наиболее часто регистрируют поражения суставов.

Цель - оценить частоту и характер поражения суставного аппарата в популяции больных В3К Московской области.

Материал и методы. Проведен ретроспективный анализ историй болезни пациентов, находившихся на стационарном обследовании и лечении в гастроэнтерологическом отделении ГБУЗ МО МОНИКИ им. М.Ф. Владимирского в период с 1 августа 2019 г. по 1 марта 2020 г. В исследование включено 70 больных с подтвержденным диагнозом ВЗК, у которых было установлено поражение суставного аппарата.

Результаты. Из 70 больных ВЗК с ВКП в виде суставных поражений 36 (51,43\%) имели диагноз болезни Крона (БК) и $34(48,57 \%)$ - язвенного колита (ЯК). В группе БК преобладали мужчины - 58,33\% ( $n=21)$, в группе ЯК их доля была $47,02 \%(n=16)$. Средний возраст установления диагноза ВЗК в группах больных ЯК и БК был сопоставим и составил $38,3 \pm 13,7$ года у мужчин с БК и $40,5 \pm 12,8$ года у мужчин с ЯК; $37,7 \pm 11,1$ года у женщин с БК и $35,7 \pm 14,0$ у женщин с ЯК. Наиболее часто среди всех больных В3К встречались рентгенонегативные периферические артралгии. Среди поражений суставов, подтвержденных лучевыми методами диагностики, сакроилеит был самой распространенной нозологической формой как среди всех больных ВЗК (24,3\%), так и в подгруппе ЯК $(17,6 \%)$, а у пациентов с БК встречался с той же частотой, что и анкилозирующий спондилоартрит (АС) - в 30,6\% случаев. АС был второй по распространенности формой поражения суставов в группах больных ЯК $(8,8 \%)$ и ВЗК (20\%) в целом. Псориатический артрит диагностирован только у пациентов с БК (у 2 из 36). Приведено описание клинического наблюдения сочетания БК и АС, осложненного развитием псориатических высыпаний на фоне лечения препаратом моноклональных антител к фактору некроза опухолей-а (анти-ФНО- $а$ ).

Заключение. Среди всех суставных поражений в нашей группе преобладали периферические артропатии. Наличие ВКП отражает более агрессивный фенотип заболевания и более высокую потребность в назначении глюкокортикостероидов. Назначение препаратов анти-ФНО-а позволяет контролировать как кишечные проявления ВЗК, так и суставной синдром, однако на фоне терапии препаратами данного класса могут развиваться лекарственно-ассоциированные поражения кожи. В этом случае возможно переключение биологической терапии на препарат другого класса, что мы продемонстрировали на нашем клиническом примере.

Ключевые слова: воспалительные заболевания кишечника, язвенный колит, болезнь Крона, внекишечные проявления, анкилозирующий спондилоартрит

Для цитирования: Таратина ОВ, Белоусова ЕА. Суставные поражения при воспалительных заболеваниях кишечника (ВЗК): анализ данных центра наблюдения больных ВЗК Московской области и клинический пример. Альманах клинической медицины. 2020;48(6):395-402. doi: 10.18786/20720505-2020-48-064.

Поступила 23.10.2020; доработана 10.12.2020; принята к публикации 11.12.2020; опубликована онлайн 17.12.2020 
$\mathrm{B}$ оспалительные заболевания кишечника (ВЗК) сегодня принято рассматривать как системные иммуновоспалительные заболевания. Частота внекишечных проявлений (ВКП) ВЗК варьирует в широком диапазоне - от 6\% [1] до 43\% [2], при этом наиболее часто регистрируют поражения суставов, кожи, глаз и реже - других органов и систем [3-5]. ВКП - атрибут более тяжелого течения ВЗК, иногда сами по себе ВКП обусловливают большую, чем поражение кишечника, тяжесть заболевания и снижают качество жизни больного [6, 7]. Почти у $50 \%$ пациентов через 30 лет после диагностики ВЗК имеются ВКП [7-9], a у $25 \%$ пациентов с болезнью Крона (БК) внекишечные симптомы в анамнезе наблюдаются еще до момента установления диагноза [10]. Раннее распознавание ВКП должно определять адекватную своевременную тактику лечения, что, безусловно, позволит предупредить развитие тяжелых осложнений и в целом будет способствовать уменьшению общего бремени заболевания.

Цель - оценить частоту и характер поражения суставного аппарата в популяции больных ВЗК в Московской области.

\section{Материал и методы}

Проведен ретроспективный анализ историй болезни пациентов, находившихся на стационарном обследовании и лечении в гастроэнтерологическом отделении ГБУЗ МО МОНИКИ им. М.Ф. Владимирского в период с 1 августа 2019 г. по 1 марта 2020 г. В исследование включено 70 больных с подтвержденным диагнозом ВЗК, у которых было установлено поражение суставного аппарата.
Все диагностические и лечебные процедуры носили общепринятый, стандартный характер, диагноз язвенного колита (ЯК) и БК устанавливался в соответствии с клиническими рекомендациями Российской гастроэнтерологической ассоциации и Ассоциации колопроктологов России по диагностике и лечению БК [11] и ЯК [12]. Все больные консультированы ревматологом, для уточнения активности и характера суставных проявлений применялась рентгенография и/или магнитно-резонансная томография (MPТ) и данные лабораторных исследований (определяли уровни ревматоидного фактора, С-реактивного белка, Антистрептолизина О, выполняли молекулярно-генетический анализ на HLA-B27). Обследование и лечение пациентов проводилось с соблюдением принципов биомедицинской этики на основе информированного добровольного согласия.

Анализировали распространенность различных нозологических форм поражения суставов в общей группе больных ВЗК, а также отдельно в группах БК и ЯК.

Статистическую обработку данных осуществляли в программе Statistica 13.2 (Dell. inc., США) методами описательной статистики. Для обобщения и оценки демографических непрерывных переменных использовали средние значения и стандартное отклонение $(\mathrm{M} \pm \sigma)$. Абсолютные цифры и проценты были рассчитаны для пациентов в пределах каждого класса болезней.

\section{Результаты}

Из 70 больных ВЗК с ВКП в виде суставных поражений 36 (51,43\%) имели диагноз БК и $34(48,57 \%)$ - ЯК. В группе БК преобладали мужчины - 58,33\% (n=21), в группе ЯК их доля была

Таблица 1. Генез и частота поражения суставов, абс. (\%)

\begin{tabular}{|c|c|c|c|}
\hline Суставные ВКП у больных ВЗК & БK & ЯК & B3K \\
\hline Все поражения суставов & $36(100)$ & $34(100)$ & $70(100)$ \\
\hline Сакроилеит & $11(30,56)$ & $6(17,65)$ & $17(24,29)$ \\
\hline Анкилозирующий спондилоартрит & $11(30,56)$ & $3(8,82)$ & $14(20,0)$ \\
\hline Ревматоидный артрит & $1(2,78)$ & $2(5,88)$ & $3(4,29)$ \\
\hline Псориатический артрит & $2(5,56)$ & 0 & $2(2,86)$ \\
\hline Другое* & $29(80,56)$ & $29(85,29)$ & $58(82,86)$ \\
\hline
\end{tabular}

БК - болезнь Крона, ВЗК - воспалительные заболевания кишечника, ВКП - внекишечные проявления, ЯК - язвенный колит "Гонартрит, энтезиты, деформирующий коксартроз, а также артралгии, не сопровождавшиеся рентгенологическими признаками поражения суставов 


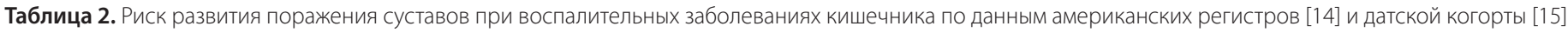

\begin{tabular}{|c|c|c|c|c|}
\hline Поражение суставов & Регистр & БK & ЯК & B3K \\
\hline \multirow[t]{3}{*}{ Заболевания костно-мышечной системы } & MarketScan & $2,55[2,20-2,96]$ & $2,15[1,88-2,46]$ & $2,14[1,93-2,37]$ \\
\hline & IMS Health & $3,29[2,87-3,78]$ & $2,87[2,52-3,27]$ & $2,88[2,60-3,19]$ \\
\hline & $\begin{array}{l}\text { Danish National Patient } \\
\text { Registry }\end{array}$ & Не исследовалось & Не исследовалось & Не исследовалось \\
\hline \multirow[t]{3}{*}{ Анкилозирующий спондилоартрит } & MarketScan & $9,38[5,40-16,30]$ & $3,72[2,18-6,35]$ & $5,83[3,93-8,64]$ \\
\hline & IMS Health & $9,03[5,99-13,62]$ & $7,18[4,69-11,01]$ & $7,79[5,61-10,83]$ \\
\hline & $\begin{array}{l}\text { Danish National Patient } \\
\text { Registry }\end{array}$ & $11,7[8,1-17,1]$ & $3,9[3,1-4,9]$ & $5,6[4,7-7,6]$ \\
\hline \multirow[t]{3}{*}{ Псориатический артрит } & MarketScan & $1,87[0,99-3,53]$ & $0,89[0,50-1,59]$ & $1,43[0,91-2,23]$ \\
\hline & IMS Health & $2,49[1,55-4,00]$ & $2,14[1,39-3,28]$ & $2,10[1,48-2,97]$ \\
\hline & $\begin{array}{l}\text { Danish National Patient } \\
\text { Registry }\end{array}$ & $1,7[1,3-2,3]$ & $1,4[1,1-1,7]$ & $1,5[1,3-1,8]$ \\
\hline \multirow[t]{3}{*}{ Ревматоидный артрит } & MarketScan & $2,37[2,02-2,77]$ & $2,16[1,88-2,49]$ & $2,05[1,84-2,29]$ \\
\hline & IMS Health & $2,76[2,40-3,18]$ & $2,76[2,40-3,18]$ & $2,72[2,43-3,04]$ \\
\hline & $\begin{array}{l}\text { Danish National Patient } \\
\text { Registry }\end{array}$ & $2,1[1,6-2,8]$ & $1,6[1,3-1,9]$ & $1,8[1,5-2,0]$ \\
\hline
\end{tabular}

БК - болезнь Крона, ВЗК - воспалительные заболевания кишечника, ЯК - язвенный колит

Данные представлены в виде отношения шансов и 95\% доверительного интервала (ОШ [95\% ДИ])

47,02\% ( $\mathrm{n}=16)$. Средний возраст установления диагноза ВЗК в группах больных ЯК и БК был сопоставим и составил: у мужчин с БК $38,3 \pm 13,7$ года, у мужчин с ЯК 40,5 $\pm 12,8$ года; у женщин с БК $37,7 \pm 11,1$ года и у женщин с ЯК $35,7 \pm 14,0$ года.

Относительная частота основных нозологических форм суставных ВКП в нашей группе пациентов представлена в табл. 1. Наиболее часто среди всех больных ВЗК встречались рентгенонегативные периферические артралгии, которые могли быть единственным проявлением суставного синдрома либо развиваться в дополнение к основной форме поражения суставов. Среди поражений суставов, подтвержденных лучевыми методами диагностики, сакроилеит был самой распространенной нозологической формой как среди всех больных ВЗК, так и в подгруппе ЯК, а у пациентов с БК встречался с той же частотой, что и АС. АС оказался второй по распространенности формой поражения суставов в группах больных ЯЗ и ВЗК в целом. Псориатрический артрит диагностирован только у пациентов с БК.

Боль и нарушение функций суставов предшествовала кишечным симптомам В3К у 9 (12,86\%) больных нашей группы: у 8 с БК (22,22\% от всех пациентов с БК) и у 1 с ЯК $(2,94 \%$ от всех больных ЯК).

\section{Обсуждение}

В популяционном французском исследовании [13] уже на момент постановки диагноза БК по крайней мере одно ВКП имели 19,1\% пациентов детского возраста (<17 лет) и 3,8\% больных в когорте старше 60 лет, а за период наблюдения (1988-2004 годы для пациентов педиатрической когорты и 1988-2006 годы для когорты пациентов пожилого возраста) новые ВКП развились в 29,8 и $5,9 \%$ случаев соответственно. По данным американских регистров [14], относительный риск поражения суставов при БК и ЯК значительно повышен (табл. 2). Анализ шведской когорты больных ВЗК [2] показал, что поражение суставов - наиболее частый вид ВКП при ВЗК и, как правило, носит иммуновоспалительный характер.

Вместе с тем в исследовании OASIS (Outcome in Ankylosing Spondylitis International Study) наиболее распространенными внескелетными проявлениями АС были увеит и ВЗК [16]. Развитие 


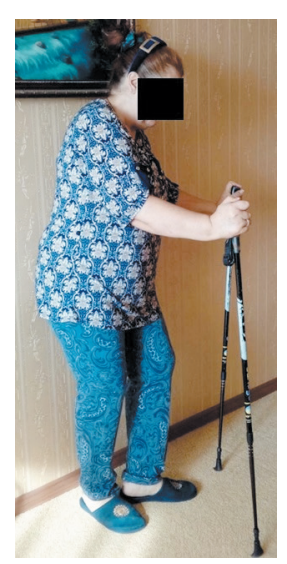

Рис. 1. Внешний вид пациентки X:: выраженные кифотические деформации грудного и шейного отделов позвоночника («поза просителя»)
ВЗК у больных АС было достоверно связано с маркерами повышенной активности АС [16].

Что касается российской популяции больных ВЗК, по данным исследования ESCApe-2 [17], ВКП имелись у 23,4\% больных ЯК и у 33,1\% пациентов с БК, при этом доминировали периферические артропатии. АС встречался только при БК, поражение периферических суставов при АС у больных БК составляло 7,2\%, аксиальных суставов - 9,4\%. На долю других артропатий в структуре всех ВКП у больных БК пришлось 53,9\% [17]. В нашей группе пациентов Московской области наиболее частым поражением суставов у больных ВЗК (как при ЯК, так и при БК) был сакроилеит $(17,65$ и $30,56 \%$ от всех поражений суставов соответственно). При БК с той же частотой, что и сакроилеит, встречался АC (30,56\%), в группе же ЯК AC (в отличие от данных ESCApe-2) тоже регистрировали, но реже $(8,82 \%)$. Как и в исследовании ESCApe-2 [17], среди суставных поражений преобладали периферические артропатии.

Гастроэнтерологическое отделение ГБУЗ МО МОНИКИ им. М.Ф. Владимирского представляет собой основной центр наблюдения больных ВЗК Московской области. И хотя прямое сравнение данных нашей группы больных с данными многолетних регистров европейских стран и США не вполне корректно, что служит ограничением нашей работы, результаты, полученные в настоящем исследовании, в целом отражают ситуацию с поражением суставного аппарата в популяции больных ВЗК Московской области.

В практическом плане важно отметить, что выраженность суставного синдрома в основном коррелирует с активностью поражения кишечника [6]. Так, у пациентов с активной стадией БК по сравнению с пациентами с неактивным заболеванием значительно чаще встречается периферический артрит $(45,1 \%$ против $31,3 \%, \mathrm{p}=0,016)$ [2]. Наличие ВКП отражает более агрессивный фенотип заболевания и более высокую потребность в назначении глюкокортикостероидов [13], при этом у пациентов как детского, так и пожилого возраста среди ВКП преобладают поражения кожи и суставов.

Приводим описание клинического наблюдения сочетания БК и АС, осложненного развитием псориатических высыпаний на фоне лечения препаратами моноклональных антител к фактору некроза опухолей- $а$ (анти-ФНО- $)$.

\section{Клиническое наблюдение}

Больная Х., 61 год. В 1996 г. в возрасте 47 лет ее стала беспокоить боль в правом голеностопном суставе, по поводу чего принимала нестероидные противовоспалительные препараты. На фоне их приема присоединилась абдоминальная боль и жидкий стул, повышение температуры тела до фебрильных цифр. При обследовании впервые установлен диагноз болезни Крона толстой кишки, тяжелая атака, потребовавшая назначения системных глюкокортикостероидов (ГКС). В качестве поддерживающей терапии применялся месалазин. Рецидивы заболевания повторялись в осенне-зимний период, купировались повторными курсами ГКС, в результате чего сформировалась стероидозависимость. В 2000 г. очередное обострение БК сопровождалось формированием ректо-вагинального свища. С целью подавления активности заболевания и преодоления гормонозависимости в комплекс терапии был включен азатиоприн, выделения из свища прекратились. При следующей атаке БК в 2004 г. была проведена одна инфузия инфликсимаба с клиническим улучшением. По административным причинам лечение генно-инженерными биологическими препаратами не было продолжено. Пациентка принимала азатиоприн, в течение 5 лет наблюдалась клиническая ремиссия, к врачу не обращалась. Осенью 2008 г. в клиническом анализе крови выявлена лейкопения, азатиоприн был отменен. У больной развилась очередная атака БК. В это же время появилась резкая боль в тазобедренных суставах и шейно-грудном отделе позвоночника с ограничением подвижности (рис. 1). С начала 2009 до конца 2010 г. больной проводилась терапия инфликсимабом с выраженной положительной динамикой со стороны кишечных проявлений БК, исчезли боли в периферических суставах и позвоночнике. С конца 2010 до мая 2016 г. принимала поддерживающую терапию сульфасалазином в суточной дозе 2-3 г. В мае 2016 г. развилась очередная атака БК.

Колоноскопия (до купола слепой кишки): просвет купола слепой кишки не деформирован, видимая слизистая розовая, множественные линейные белесые рубцы. Восходящая, поперечная, нисходящая, сигмовидная ободочная кишка: просвет не деформирован, на слизистой множественные линейные белесые рубцы. Прямая кишка: просвет не деформирован, слизистая гиперемирована. В нижнеампулярном отделе единичные язвы линейной формы $0,3 \times 0,5$ см. Заключение: болезнь Крона, фаза рубцевания.

Мультиспиральная компьютерная томография органов брюшной полости и забрюшинного пространства от 17.05.2016 (рис. 2): определяется равномерное циркулярное утолщение стенки прямой кишки и начальных отделов сигмовидной кишки с неравномерным сужением просвета последней. На уровнях сканирования пояснично-крестцового отдела позвоночника определяется равномерное слабовыраженное обызвествление передней продольной 

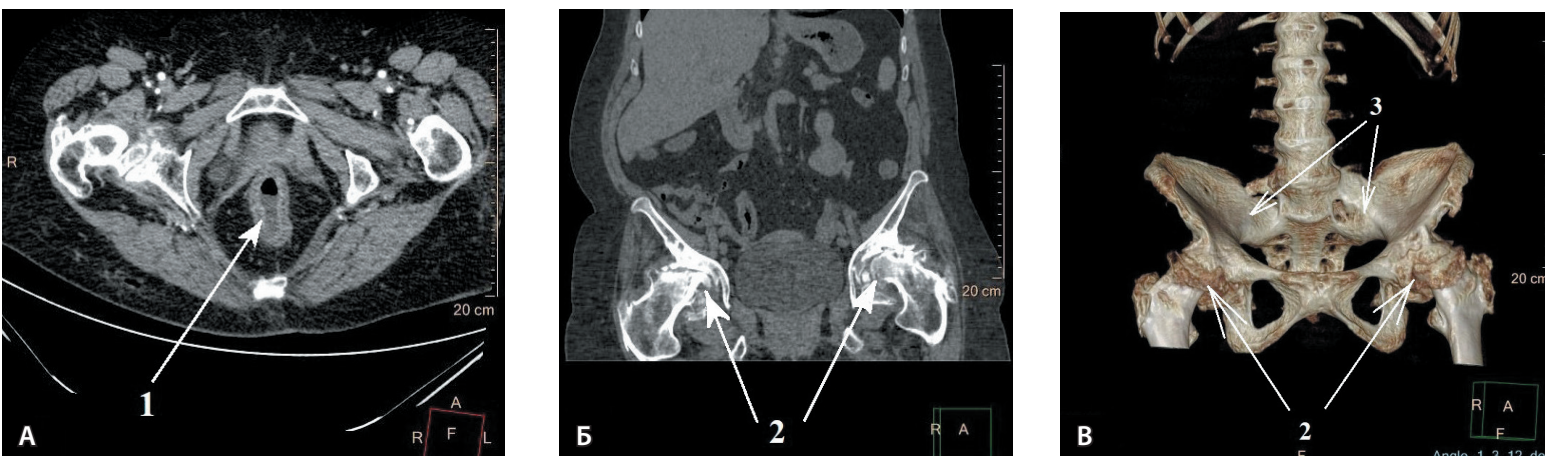

Рис. 2. МРТ-визуализация поражения кишечника (А) и суставов (Б) и трехмерная реконструкция костно-суставного аппарата по данным МРТ (B). Отмечается равномерное циркулярное утолщение стенки прямой кишки с преобладанием в ней жирового компонента (А, стрелка 1); значительное сужение суставной щели левого и отсутствие суставной щели правого тазобедренных суставов; множественные остеофиты головок обеих бедренных костей (Б и В, стрелки 2); отсутствие суставных щелей правого и левого крестцово-позвоночных сочленений (В, стрелки 3)

связки вдоль всего отмеченного отдела позвоночника. Заключение: картина выявленных изменений тонкой и толстой кишки не противоречит диагнозу БК. Данных за острое воспаление и стриктуры не отмечено. Зафиксированные изменения костной ткани более характерны для болезни Бехтерева. Двусторонний коксартроз. Анкилоз крестцово-позвоночных сочленений.

С июня 2016 г. начата терапия цертолизумаба пэголом с положительным клиническим эффектом. В ноябре 2017 г. больная отметила появление бляшек с шелушащейся поверхностью на нижних конечностях (рис. 3). Больная консультирована дерматологом, установлен диагноз распространенного вульгарного псориаза, рекомендовано местное лечение бетаметазоном и салициловой кислотой.

Колоноскопия от 06.02.2018: слепая, восходящая поперечно-ободочная, нисходящая, сигмовидная кишка - без патологии. В области ректосигмоидного перехода - множественные линейные белесоватые рубцы до 0,2 см, просвет кишки не сужен. Прямая кишка: слизистая бледно-розовая, в нижнеампулярном отделе участок рыхлой гиперемированной слизистой, сосудистый рисунок несколько обеднен. Заключение: болезнь Крона с активностью в прямой кишке.

МРТ суставов от 14.02.2018: головка бедренной кости с обеих сторон резко уплощена, грубо деформирована, с формированием выраженных костных разрастаний по краям суставной поверхности; контуры ее четкие, неровные; расположена в суставной впадине. Структура и интенсивность сигнала костной ткани проксимального отдела бедренной кости изменена, грубо нарушена за счет разнокалиберных очагов отека. Суставная впадина с обеих сторон углублена, деформирована, с грубыми костными разрастаниями по краям суставных поверхностей. В полости тазобедренного сустава с обеих сторон избыточное количество внутрисуставной жидкости не выявляется. Заключение: картина грубой деформации тазобедренных суставов у пациента, длительно страдающего болезнью Бехтерева.

Больная консультирована ревматологом, диагноз: анкилозирующий спондилоартрит, HLA-B27(-), двусторонний сакроилеит 4 ст. (анкилоз крестцово-подвздошных сочленений) с внеаксиальными проявлениями. Периферический полиартрит, энтезиты. Асептический некроз головки бедренной кости? Рекомендовано продолжить терапию цертолизумаба пэголом по поддерживающей схеме, к терапии добавить метотрексат в дозе 10 мг в неделю и сульфасалазин 3 г/сут, рассмотреть вопрос об эндопротезировании тазобедренных суставов.
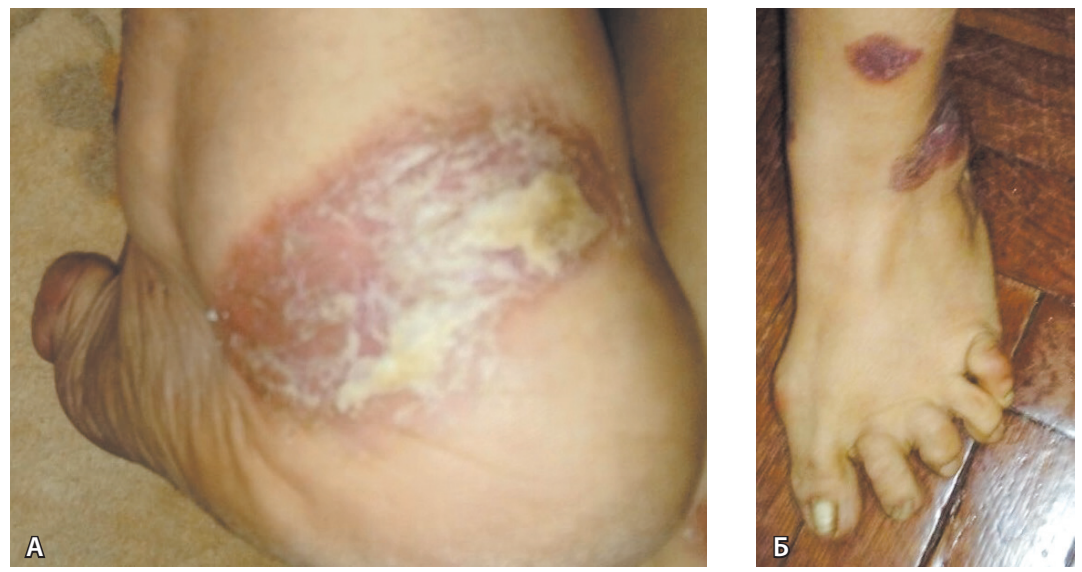

Рис. 3. Псориазоподобные высыпания на коже правой (А) и левой (Б) нижних конечностей. Высыпания представлены бляшками розово-красного цвета с четкими границами, шелушением по всей поверхности; серовато-желтыми чешуе-корками, плотно прилегающими к поверхности бляшек (A) 
Пациентке проведено оперативное лечение (эндопротезирование обоих тазобедренных суставов). Сучетом возникновения на фоне терапии анти-ФНО- $а$ псориаза de novo и неэффективности топической терапии в марте 2020 г. рекомендована замена терапии на устекинумаб, который в 2020 г. зарегистрирован в Российской Федерации для лечения БК.

\section{Обсуждение клинического наблюдения}

Кожные осложнения антицитокиновой терапии встречаются в 22-25\% случаев, чаще у женщин, не связаны с активностью заболевания и возникают на фоне любого препарата из группы анти-ФНО-а, применяющихся для лечения БК (инфликсимаб, адалимумаб или цертолизумаба пегол) $[18,19]$. Согласно положению ЕССО 6С [6], лечение препаратами анти-ФНО-а может индуцировать парадоксальное воспаление кожи (уровень доказательности 3), которое является класс-специфическим эффектом и обычно разрешается при отмене препарата. К лекарственно индуцированным поражениям кожи относят: ксероз, экзему, псориазиформный дерматит, псориаз, пальмоплантарный пустулез, алопецию и другие [19]. Обычно они возникают в течение нескольких месяцев - года после начала терапии, в отдельных случаях в течение недели после первой инъекции [19]. При появлении таких осложнений рекомендуется консультация дерматолога, в большинстве случаев возможен контроль данных явлений с помощью местного лечения, а терапия анти-ФНО- $а$ может быть продолжена

\section{Дополнительная информация}

Согласие пациента
Пациентка добровольно подписала информированное согласие на пу-
бликацию персональной медицинской информации в обезличенной
форме и фотографий в журнале «Альманах клинической медицины».
Финансирование
Работа проведена без привлечения дополнительного финансирова-
ния со стороны третьих лиц.

(уровень доказательности 3) [6]. Вместе с тем, поскольку этот тип поражений кожи класс-специфичен для препаратов анти-ФНО-а, переключение на другой вид моноклональных антител к ФНО-а нецелесообразно, и рекомендуется замена генно-инженерной терапии на препарат другого класса: устекинумаб или ведолизумаб [20]. При сочетании БК с поражением суставов и псориазом кожи, псориатическим артритом или при псориазоподобных эффектах препаратов анти-ФНО-а препаратом выбора признан устекинумаб (моноклональные антитела к интерлейкинам 12/23).

\section{Заключение}

Суставной синдром у больных ВЗК не только спутник, но и нередко предиктор тяжелого течения, развития осложнений, обычно коррелирует с активностью поражения кишечника. В приведенном клиническом наблюдении суставные проявления болезни Крона возникли еще до манифестации кишечных симптомов, при прогрессировании заболевания их тяжесть вышла на первый план и значительно снижала качество жизни нашей пациентки. Терапия препаратами анти-ФНО-а позволяла контролировать активность как поражения кишки, так и суставного синдрома, однако привела к возникновению медикаментозно-индуцированных кожных проявлений (псориаза), что вызвало смену генно-инженерной антицитокиновой терапии на препарат другого класса. (\$)

\section{Конфликт интересов}

Авторы декларируют отсутствие конфликта интересов при написании данной статьи.

\section{Участие авторов}

Оба автора внесли равный вклад в проведение исследования и подготовку статьи, прочли и одобрили финальную версию перед публикацией.

\section{Литература / References}

1. Bernstein CN, Blanchard JF, Rawsthorne P, Yu N. The prevalence of extraintestinal diseases in inflammatory bowel disease: a population-based study. Am J Gastroenterol. 2001;96(4):1116-22. doi: 10.1111/j.1572-0241.2001.03756.x.

2. Vavricka SR, Brun L, Ballabeni P, Pittet V, Prinz Vavricka BM, Zeitz J, Rogler G, Schoepfer AM. Frequency and risk factors for extraintestinal manifestations in the Swiss inflammatory bowel disease cohort. Am J Gastroenterol. 2011;106(1): 110-9. doi: 10.1038/ajg.2010.343.
3. Ott C, Schölmerich J. Extraintestinal manifestations and complications in IBD. Nat Rev Gastroenterol Hepatol. 2013;10(10):585-95. doi: 10.1038/nrgastro.2013.117.

4. Veloso FT. Extraintestinal manifestations of inflammatory bowel disease: do they influence treatment and outcome? World J Gastroenterol. 2011;17(22):2702-7. doi: 10.3748/wjg.v17. i22.2702.

5. Zippi M, Corrado C, Pica R, Avallone EV, Cassieri C, De Nitto D, Paoluzi P, Vernia P. Extraintestinal manifestations in a large series of Italian inflammatory bowel disease patients. World J Gastroenterol. 2014;20(46):17463-7. doi: 10.3748/wjg. v20.i46.17463.

6. Harbord M, Annese V, Vavricka SR, Allez M, Barreiro-de Acosta M, Boberg KM, Burisch J, De Vos $M$, De Vries $A M$, Dick $A D$, Juillerat $\mathrm{P}$, Karlsen $\mathrm{TH}$, Koutroubakis I, Lakatos $\mathrm{PL}$, Orchard T, Papay P, Raine T, Reinshagen M, Thaci D, Tilg H, Carbonnel F; European Crohn's and Colitis Organisation. The First European Evidence-based 
Consensus on Extra-intestinal Manifestations in Inflammatory Bowel Disease. J Crohns Colitis. 2016;10(3):239-54. doi: 10.1093/ecco-jcc/jjv213.

7. Vavricka SR, Schoepfer A, Scharl M, Lakatos PL, Navarini A, Rogler G. Extraintestinal Manifestations of Inflammatory Bowel Disease. Inflamm Bowel Dis. 2015;21(8):1982-92. doi: 10.1097/ MIB.0000000000000392.

8. Ardizzone S, Puttini PS, Cassinotti A, Porro GB Extraintestinal manifestations of inflammatory bowel disease. Dig Liver Dis. 2008;40 Suppl 2: S253-9. doi: 10.1016/S1590-8658(08)60534-4.

9. Levine JS, Burakoff R. Extraintestinal manifestations of inflammatory bowel disease. Gastroenterol Hepatol (NY). 2011;7(4):235-41.

10. Vavricka SR, Rogler G, Gantenbein C, Spoerri $M$, Prinz Vavricka $M$, Navarini $A A$, French $L E$, Safroneeva $E$, Fournier $N$, Straumann A, Froehlich F, Fried M, Michetti P, Seibold F, Lakatos PL, Peyrin-Biroulet L, Schoepfer AM. Chronological Order of Appearance of Extraintestinal Manifestations Relative to the Time of IBD Diagnosis in the Swiss Inflammatory Bowel Disease Cohort. Inflamm Bowel Dis. 2015;21(8):1794-800. doi: $10.1097 / \mathrm{MIB} .0000000000000429$.

11. Ивашкин ВТ, Шелыгин ЮА, Халиф ИЛ, Белоусова ЕА, Шифрин ОС, Абдулганиева ДИ, Абдулхаков РА, Алексеева ОП, Алексеенко СА, Ачкасов СИ, Барановский АЮ, Болихов КВ, Валуйских ЕЮ, Варданян АВ, Веселов АВ, Веселов ВВ, Головенко АО, Головенко ОВ, Григорьев ЕГ, Губонина ИВ, Жигалова ТН, Кашников ВН, Кизова ЕА, Князев ОВ, Костенко НВ, Куляпин $\mathrm{AB}$, Морозова НА, Муравьев $\mathrm{AB}$, Низов АА, Никитина НВ, Николаева НН, Никулина НВ, Одинцова АХ, Осипенко МФ, Павленко ВВ, Парфенов АИ, Полуэктова ЕА, Потапов АС, Румянцев ВГ, Светлова ИО, Ситкин СИ, Тимербулатов ВМ, Ткачев АВ, Ткаченко ЕВ, Фролов СА, Хубезов ДА, Чашкова ЕЮ, Шапина МВ, Щукина ОБ, Яковлев АА. Клинические рекомендации Российской гастроэнтерологической ассоциации и Ассоциации колопроктологов России по диагностике и лечению болезни Крона. Колопроктология. 2017;60(2):7-29. doi: 10.33878/2073-7556-20170-2-7-29. [Ivashkin VT, Shelygin YuA, Khalif IL, Belousova EA, Shifrin OS, Abdulganieva DI, Abdulkhakov RA, Alekseeva OP, Alekseenko SA, Achkasov SI, Baranovsky AYu, Bolikhov KV, Valuiskikh EYu, Vardanyan AV, Veselov AV, Veselov VV, Golovenko AO, Golovenko OV, Gubonina IV, Zhigalova TN, Kashnikov VN, Knyazev OV, Kostenko NV, Kulyapin AV, Morozova NA, Muravev AV, Nizov AA, Nikitina NV, Nikolaeva NN, Osipenko MF, Pavlenko VV, Parfenov Al, Poluektova EA, Potapov AS, Rumyantsev VG, Svetlova IO, Sitkin SI, Timerbulatov VM, Tkachev AV, Tkachenko EV, Frolov SA, Chashkova EYu, Shapina MV, Shchukina OB, Yakovlev AA. [Clinical guide of
Russian Association of Gastroenterology and Russian Association of Coloproctology on diagnostics and treatment of Crohn's disease]. Koloproktologia [Coloproctology]. 2017;60(2):7-29. Russian. doi: 10.33878/2073-7556-2017-0-2-729.]

12. Ивашкин ВТ, Шелыгин ЮА, Халиф ИЛ, Белоусова ЕА, Шифрин ОС, Абдулганиева ДИ, Абдулхаков РА, Алексеева ОП, Алексеенко СА, Ачкасов СИ, Барановский АЮ, Болихов КВ, Валуйских ЕЮ, Варданян АВ, Веселов АВ, Веселов ВВ, Головенко АО, Головенко ОВ, Григорьев ЕГ, Губонина ИВ, Жигалова ТН, Кашников ВН, Кизова ЕА, Князев ОВ, Костенко НВ, Куляпин АВ, Морозова НА, Муравьев АВ, Низов АА, Никитина НВ, Николаева НН, Никулина НВ, Одинцова АХ, Осипенко МФ, Павленко ВВ, Парфенов АИ, Полуэктова ЕА, Потапов АС, Румянцев ВГ, Светлова ИО, Ситкин СИ, Тимербулатов ВМ, Ткачев АВ, Ткаченко ЕИ, Фролов СА, Хубезов ДА, Чашкова ЕЮ, Шапина МВ, Щукина ОБ, Яковлев АА. Клинические рекомендации Российской гастроэнтерологической ассоциации и Ассоциации колопроктологов России по диагностике и лечению язвенного колита. Колопроктология. 2017;59(1):6-30. [lvashkin VT, Shelygin YuA, Khalif IL, Belousova EA, Shifrin OS, Abdulganieva Dl, Abdulkhakov RA, Alekseeva OP, Alekseenko SA, Achkasov SI, Baranovsky AYu, Bolikhov KV Valuiskikh EYu, Vardanyan AV, Veselov AV, Veselov VV, Golovenko AO, Golovenko OV, Grigorev EG, Gubonina IV, Zhigalova TN, Kashnikov VN, Knyazev OV, Kostenko NV, Kulyapin AV, Morozova NA, Muravev AV, Nizov AA, Nikitina NV, Nikolaeva NN, Osipenko MF, Pavlenko VV, Parfenov Al, Poluektova EA, Potapov AS, Rumyantsev VG, Svetlova IO, Sitkin SI, Timerbulatov VM, Tkachev AV, Tkachenko El, Frolov SA, Khubezov DA, Chashkova EYu, Shapina MV, Shchukina OB, Yakovlev AA. [Clinical guide of Russian Association of Gastroenterology and Russian Association of Coloproctology on diagnostics and treatment of ulcerative colitis]. Koloproktologia [Coloproctology]. 2017;59(1):6-30. Russian.]

13. Duricova D, Sarter H, Savoye G, Leroyer A, Pariente $B$, Armengol-Debeir $L$, Bouguen $G$, Ley $D_{\text {, }}$ Turck D, Templier C, Buche S, Peyrin-Biroulet L, Gower-Rousseau C, Fumery M; Epimad Group. Impact of Extra-Intestinal Manifestations at Diagnosis on Disease Outcome in Pediatric- and Elderly-Onset Crohn's Disease: A French Population-Based Study. Inflamm Bowel Dis. 2019;25(2): 394-402. doi: 10.1093/ibd/izy254.

14. Cohen R, Robinson D Jr, Paramore C, Fraeman K, Renahan K, Bala M. Autoimmune disease concomitance among inflammatory bowel disease patients in the United States, 2001-2002. Inflamm Bowel Dis. 2008;14(6):738-43. doi: 10.1002/ibd.20406.
15. Halling ML, Kjeldsen J, Knudsen T, Nielsen J, Hansen LK. Patients with inflammatory bowel disease have increased risk of autoimmune and inflammatory diseases. World J Gastroenterol. 2017;23(33):6137-46. doi: 10.3748/wjg.v23. i33.6137.

16. Essers I, Ramiro S, Stolwijk C, Blaauw $M$, Landewé $R$, van der Heijde $D$, Van den Bosch $F$, Dougados $M$, van Tubergen A. Characteristics associated with the presence and development of extra-articular manifestations in ankylosing spondylitis: 12-year results from OASIS. Rheumatology (Oxford). 2015;54(4):633-40. doi: 10.1093/ rheumatology/keu388.

17. Белоусова ЕА, Абдулганиева ДИ, Алексеева ОП, Алексеенко СА, Барановский АЮ, Валуйских ЕЮ, Головенко АО, Головенко ОВ, Жигалова $\mathrm{TH}$, Князев ОВ, Куляпин $\mathrm{AB}$, Лахин $\mathrm{AB}$, Ливзан МА, Лубянская ТГ, Николаева НН, Никитина НВ, Никулина ИВ, Осипенко МФ, Павленко ВВ, Парфенов АИ, Рогачиков ЮЕ, Светлова ИО, Ткачев АВ, Ткаченко ЕИ, Халиф ИЛ, Чашкова ЕЮ, Щукина ОБ, Язенок НС, Яковлев АА. Социально-демографическая характеристика, особенности течения и варианты лечения воспалительных заболеваний кишечника в России. Результаты двух многоцентровых исследований. Альманах клинической медицины. 2018;46(5):445-63. doi: 10.18786/2072-0505-2018-46-5-445-463. [Belousova EA, Abdulganieva DI, Alexeeva OP, Alexeenko SA, Baranovsky AYu, Valuyskikh EYu, Golovenko AO, Golovenko OV, Zhigalova TN, Knyazev OV, Kulyapin AV, Lakhin AV, Livzan MA, Lubyanskaya TG, Nikolaeva NN, Nikitina NV, Nikulina IV, Osipenko MF, Pavlenko VV, Parfenov Al, Rogachikov YE, Svetlova IO, Tkachev AV, Tkachenko El, Khalif IL, Chashkova EYu, Shchukina OB, Yazenok NS, Yakovlev AA. [Social and demographic characteristics, features of disease course and treatment options of inflammatory bowel disease in Russia: results of two multicenter studies]. Almanac of Clinical Medicine. 2018;46(5):445-63. Russian. doi: 10.18786/20720505-2018-46-5-445-463.]

18. Fiorino G, Omodei PD. Psoriasis and Inflammatory Bowel Disease: Two Sides of the Same Coin? J Crohns Colitis. 2015;9(9):697-8. doi: 10.1093/ ecco-jcc/jjv110.

19. Segaert S, Hermans C. Clinical Signs, Pathophysiology and Management of Cutaneous Side Effects of Anti-Tumor Necrosis Factor Agents. Am J Clin Dermatol. 2017;18(6):771-87. doi: 10.1007/ s40257-017-0296-7.

20. Ungureanu L, Cosgarea R, Alexandru Badea M, Florentina Vasilovici A, Cosgarea I, Corina Șenilă $S$. Cutaneous manifestations in inflammatory bowel disease (Review). Exp Ther Med. 2020;20(1):31-7. doi: 10.3892/etm.2019.8321. 


\title{
Joint lesions in inflammatory bowel diseases: the analysis of the Moscow regional patient registry and a clinical case
}

\author{
O.V. Taratina' $•$ E.A. Belousova'
}

Rationale: Extraintestinal manifestations (EIM) of an inflammatory bowel disease (IBD) are a sign of its more severe course. Joint lesions are most common among IBD EIM.

Aim: To evaluate the prevalence and types of joint lesions in the population of IBD patients of the Moscow region.

Materials and methods: We performed a retrospective analysis of medical files of the patients who were admitted to the Moscow Region Inflammatory Bowel Disease Center (MONIKI) for examination and treatment from August 1, 2019, to March 1, 2020. The study included 70 patients with confirmed diagnoses of IBD and confirmed or suspected involvement of the joints.

Results: Thirty six of 70 patients with IBD and EIM (51.43\%) had been diagnosed with Crohn's disease (CD), and 34 (48.57\%) with ulcerative colitis (UC). The CD group included more men $(n=21,58.33 \%)$, whereas their proportion in the UC group was $47.02 \%(n=16)$. The mean age at $C D$ diagnosis in the UC and CD groups was comparable: $38.3 \pm 13.7$ years in men with $C D$ and $40.5 \pm 12.8$ years in men with UC, $37.7 \pm 11.1$ years in women with $C D$ and $35.7 \pm 14.0$ in women with UC. The most prevalent among all IBD patients were X-ray negative peripheral arthralgias. Among joint lesions confirmed by radiological diagnostics, sacroileitis was most prevalent both in all IBD patients (24.3\%), as well as in the UC group (17.6\%), whereas in the $C D$ patients its frequency was the same as that of ankylosing spondyloarthritis (AS)
(30.6\% of the cases). AS ranked second in the prevalence of joint lesions in the UC group (8.8\%) and all IBD (20\%). Psoriatic arthritis was diagnosed only in the CD patients $(2 / 36)$.

We describe a clinical case of $C D$ with AS, complicated with psoriatic rash, treated with a monoclonal antibody to tumor necrosis factor alfa (anti-TNF-a).

Conclusion: Peripheral arthropathias were most prevalent among all joint lesions in the group studied. EIM mirror a more aggressive phenotype of the disease and higher glucocorticosteroids requirements. Administration of anti-TNF- $a$ agents allows for the control of both intestinal IBD manifestations and of the joint syndrome. However, drug-associated skin adverse event can occur during treatment with this drug class. In such a case, it is possible to switch the biological therapy to another class of drugs that we have demonstrated with the given clinical example.

Key words: inflammatory bowel disease, ulcerative colitis, Crohn's disease, extraintestinal manifestations, ankylosing spondyloarthritis

For citation: Taratina OV, Belousova EA. Joint lesions in inflammatory bowel diseases: the analysis of the Moscow regional patient registry and a clinical case. Almanac of Clinical Medicine. 2020;48(6):395402 doi: 10.18786/2072-0505-2020-48-064

Received 23 October 2020; revised 10 December 2020; accepted 11 December 2020; published online 17 December 2020

\section{Informed consent statement}

The patient has voluntarily signed her informed consent for the publication of her personal medical information and photo content in the Almanac of Clinical Medicine journal.

\section{Conflict of interests}

The authors declare no conflict of interests.

\section{Authors' contributions}

Both authors have contributed equally to the study conduct and preparation of the paper, have read and approved its final version before the publication.

Olesya V. Taratina - MD, PhD, Research Fellow, Department of Gastroenterology; Associate Professor, Chair of Gastroenterology, Postgraduate Training Faculty ${ }^{1}$; ORCID: http://orcid.org/0000-00016112-6609

$\triangle 61 / 2$ Shchepkina ul., Moscow, 129110, Russian Federation. Tel.: +7 (926) 2456659

E-mail: taratina.o@gmail.com

Elena A. Belousova - MD, PhD, Professor, Head of Department of Gastroenterology, Chief of Chair of Gastroenterology, Postgraduate Training Faculty'; ORCID: http://orcid.org/0000-0003-4523-3337 